\title{
ANÁLISE DAS TRANSFORMAÇÕES AMBIENTAIS DA PORÇÃO CENTRAL DO ESTADO DO TOCANTINS: ÊNFASE NOS ASPECTOS DE USO E OCUPAÇÃO DA TERRA NO MUNICÍPIO DE BREJINHO DE NAZARÉ
}

Analysis of environmental transformations in the central portion of the state of Tocantins: emphasis on aspects of land use and occupation in the municipality of Brejinho de Nazaré

Análisis de transformaciones ambientales en la parte central del estado de Tocantins: énfasis en aspectos de uso de la tierra y ocupación en el municipio de Brejinho de Nazaré

\section{José Paulo da Silva Noleto ${ }^{1}$, Sandro Sidnei Vargas de Cristo ${ }^{2 *}$}

${ }^{1}$ Graduando em Geografia, Universidade Federal do Tocantins, Porto Nacional, Brasil.

${ }^{2}$ Professor do Curso de Geografia, Universidade Federal do Tocantins, Porto Nacional, Brasil.

*Correspondência: Rua 03. Quadra 17, sn ${ }^{\circ}$, Jardim dos Ipês, Bloco IV, Sala do LABGEOP, 77.500.000, Porto Nacional/Tocantins.email:| sidneicristo@uft.edu.br

Artigo recebido em 27/03/2020 aprovado em 25/08/2020 publicado em 30/10/2020.

\section{RESUMO}

O presente trabalho refere-se à análise das transformações ambientais da porção central do estado do Tocantins, dando-se ênfase aos aspectos de Uso e Ocupação da Terra do município de Brejinho de Nazaré entre os anos de 1985 a 2018. Neste sentido tem como principal objetivo verificar as transformações que ocorreram no ambiente do município em questão, relacionados aos diferentes modos de Uso e Ocupação da Terra. Como método optou-se pelas técnicas de Sensoriamento Remoto onde fez-se uso de imagens de satélites Landsat, sensor TM (Thematic Mapper) dos anos de 1985, 1995 e 2005 e do sensor OLI (Operational Land Imager) dos anos de 2015,e 2018 ambas com resolução espacial de 30 metros, obtidas gratuitamente via site do USGS - United States Geological Survey. Os softwares utilizados foram QGIS versão 2.18.2, Spring versão 5.5 do INPE e o ArcGis Desktop versão 10.5.1 da ESRI. De maneira geral, os resultados proporcionaram a observação de significativas transformações ambientais que ocorreram no município em decorrência do Uso e Ocupação da Terra, destacando-se principalmente a redução da vegetação de Cerrado em prol das atividades agropecuárias desenvolvidas. Destaca-se também a importância do uso das técnicas de Sensoriamento Remoto para analisar a evolução das transformações ambientais e os aspectos de Uso e Ocupação da Terra como ferramenta de gestão ambiental e planejamento de uso.

Palavras-chave: Uso e ocupação da Terra; Sensoriamento Remoto; Transformações Ambientais.

\section{ABSTRACT}

The present work refers to the analysis of the environmental transformations of the central portion of the state of Tocantins, with emphasis on the aspects of Land Use and Occupation in the municipality of Brejinho de Nazaré between the years 1985 to 2018. In this sense, it has as main objective to verify the transformations that occurred in the environment of the municipality in question, related to the different modes of Use and Occupation of the Land. As a method, Remote Sensing techniques were used, using Landsat satellite images, TM sensor (Thematic Mapper) from 1985, 1995 and 2005 and OLI sensor (Operational Land Imager) from 2015 and 2018, both with spatial resolution of 30 meters, obtained free of charge via the USGS - United States Geological Survey website. The software used was QGIS version 2.18.2, spring version 5.5 from INPE and ArcGIS Desktop version 10.5.1 from ESRI. In general, the results provided the observation of significant environmental changes that occurred in the municipality due to the Use and Occupation of the Land, with emphasis on the reduction of Cerrado vegetation in 
favor of the agricultural activities developed. It also highlights the importance of using Remote Sensing techniques to analyze the evolution of environmental changes and the Land Use and Occupation aspects as an environmental management and use-planning tool.

Keywords: Land use and occupation; Remote sensing; Environmental Transformations.

\section{RESUMEN}

El presente trabajo se refiere al análisis de las transformaciones ambientales de la porción central del estado de Tocantins, con énfasis en los aspectos de Uso y Ocupación de la Tierra en el municipio de Brejinho de Nazaré entre los años 1985 a 2018. En este sentido, tiene como principal objetivo verificar los cambios ocurridos en el entorno del municipio en cuestión, en relación con los diferentes modos de uso y ocupación de la tierra. Como método, se utilizaron técnicas de teledetección, utilizando imágenes satelitales Landsat, sensor TM (Thematic Mapper) de 1985, 1995 y 2005 y sensor OLI (Operational Land Imager) de 2015 y 2018, ambos con resolución espacial de 30 metros, obtenida de forma gratuita a través del sitio web USGS - United States Geological Survey. El software utilizado fue QGIS versión 2.18.2, Spring versión 5.5 de INPE y ArcGis Desktop versión 10.5.1 de ESRI. En general, los resultados proporcionaron la observación de cambios ambientales significativos que ocurrieron en el municipio debido al uso y ocupación de la tierra, con énfasis en la reducción de la vegetación del Cerrado a favor de las actividades agrícolas desarrolladas. También destaca la importancia de utilizar técnicas de Teledetección para analizar la evolución de los cambios ambientales y los aspectos de Uso y Ocupación de la Tierra como una herramienta de gestión ambiental y planificación del usos.

Descriptores: Uso de la tierra y ocupación; Detección remota; Transformaciones Ambientales.

\section{INTRODUÇÃO}

Considerando as significativas transformações ambientais relacionadas aos aspectos de uso e ocupação da Terra decorrentes das diferentes formas de utilização do espaço pelo ser humano, percebidas atualmente em âmbito mundial, é que são cada vez maiores as preocupações e a busca por respostas a esta questão. Neste sentido são percebidos diversos problemas e consequências ambientais que podem ser exemplificadas no Brasil, como a intensa expansão de atividades agrícolas que utilizam grandes porções territoriais em detrimento da cobertura vegetal natural, os quais podem ser observados nos diversos biomas. No estado do Tocantins, a questão ambiental se assemelha e cada vez mais é perceptível a transformação que tem sofrido o Cerrado em decorrência da expansão de atividades econômicas ligadas aos modos de uso e ocupação da terra pelo ser humano, principalmente pelas atividades ligadas à agropecuária e a urbanização. Assim, são diversos os aspectos ambientais e as transformações que tem atingido a fauna, que fica desprotegida e sem alimentação, a flora que perde sua diversidade e os aspectos abióticos como as águas que perdem qualidade e quantidade, os solos que são contaminados, entre outros aspectos que se degradam. Com esta preocupação é que a presente pesquisa foi desenvolvida, visando analisar as transformações ambientais da porção central do estado do Tocantins dando-se ênfase nos aspectos de Uso e Ocupação da Terra no município de Brejinho de Nazaré utilizando-se técnicas de Sensoriamento Remoto. Com o uso destas técnicas é possível analisar-se grandes porções de áreas territoriais, como é o caso do município em questão, buscando-se contribuir com o conhecimento e informações sobre as diferentes formas de uso e ocupação que ocorrem e ocorreram, bem como suas consequências quanto aos aspectos de evolução e transformação ambiental. De maneira geral a analise temporal realizada por meio de imagens de satélite, entre os anos de 1985 e 2018, pode servir de subsídio aos setores responsáveis pelo planejamento urbano e conservação ambiental do município auxiliando na melhoria dos aspectos de uso e ocupação, bem como na tomada de medidas que visem minimizar as 
transformações e as perdas ambientais locais. Ainda, com a realização da presente pesquisa, buscou-se o entendimento da forma e distribuição do uso e ocupação da terra no município, bem como saber sobre a intensidade das transformações ambientais e a degradação a que este território é submetido.

\section{MATERIAIS E MÉTODO}

\section{Materiais}

Livros, artigos e materiais bibliográficos sobre o tema e área de pesquisa adquiridos via internet e consultas a biblioteca; Imagens de satélites com resolução espacial de 30 metros, obtidas gratuitamente via site do USGS - United States Geological Survey. Landsat sensor TM (Thematic Mapper) dos anos de 1985, 1995 e 2005; Landsat sensor OLI (Operational Land Imager) dos anos de 2015 e 2018; Cartas topográficas na escala 1:100.000 da (DSG) Diretoria de Serviço Geográfico do Exército: Folhas de Brejinho de Nazaré, Fátima, Santa Rosa e Porto Nacional; Arquivos vetoriais disponibilizados gratuitamente no site da SEPLAN (Secretaria do Planejamento e Orçamento do Estado do Tocantins); Software QGIS versão 2.18.2; Software Spring versão 5.5 do INPE; Software ArcGis Desktop versão 10.5.1 da ESRI; Máquina fotográfica digital; Receptor de navegação do Sistema de Posicionamento Global - GPS.

\section{Método}

Para realização da pesquisa fez-se a utilização de técnicas de Sensoriamento Remoto aplicadas via Geoprocessamento onde de maneira geral o limite do município de Brejinho de Nazaré serviu de base para realização de mosaicos de cartas topográficas e imagens de satélites. De modo específico foram levantadas as imagens que abrangiam o município que pudessem proporcionar a observação dos aspectos ambientais e de Uso e Ocupação da Terra entre os anos de 1985 e 2018. Neste caso foram utilizadas as imagens de satélites
Landsat dos anos de 1985 sensor TM, de 1995 sensor TM, de 2005 sensor TM (Bandas 3, 4 e 5), dos anos de 2015 e 2018 sensor OLI (Bandas 5, 4 e 3), com as quais foi possível realizar-se composições coloridas, bem como realizar-se a classificação supervisionada das mesmas, via software ArcGis. Assim, deu-se ênfase aos diferentes tipos de uso e ocupação no período em questão, ou seja, realização de uma análise temporal da área do município observando-se as transformações ambientais e os diferentes modos de uso e ocupação.

Na sequência, realizou-se trabalho de campo para análise e descrição dos diferentes tipos de uso e ocupação, das transformações e degradação ambiental, bem como a aferição dos mapas confeccionados no Laboratório de Geoprocessamento do Curso de Geografia - Campus de Porto Nacional - UFT.

\section{RESULTADOS E DISCUSSÃO}

Com a pesquisa realizou-se uma análise evolutiva dos aspectos de Uso e Ocupação da Terra do município de Brejinho de Nazaré (Figura 1), entre os anos de 1985 a 2018. Entre os aspectos, destacou-se os usos relacionados a Agropecuária e a Cobertura Vegetal de Cerrado.

Figura 1. Localização do município de Brejinho de Nazaré Tocantins

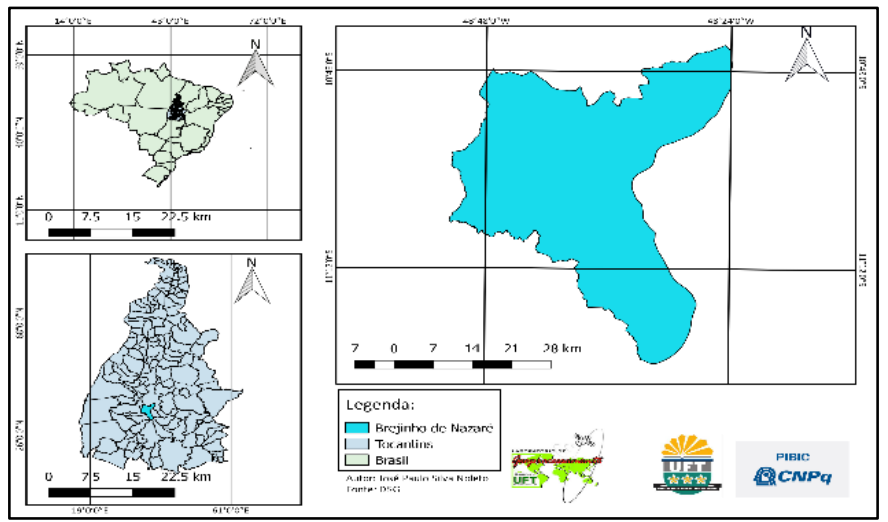

Elaboração: José Paulo da S. Noleto, 2019.

Em 1985 (Figura 2) observa-se que a área de Cerrado Denso e Ralo abrangem uma área significativa do município em questão, ficando suas concentrações 
distribuídas nas porções, central, noroeste e norte, localizadas nas áreas mais elevadas.

Os corpos de água de maneira geral encontramse distribuídos pelas diversas porções da área de estudo, representados pelas represas e cursos fluviais com destaque para o rio Tocantins que ocupa uma faixa que se estende no sentido norte-sul, servindo como limite leste do município.

As áreas de uso agropecuário também aparecem de maneira significativa no município, distribuídas em praticamente todas as porções, com concentrações nas porções sul, sudeste e nordeste.

Figura 2. Uso e Ocupação da Terra do município de Brejinho de Nazaré - Tocantins em 1985

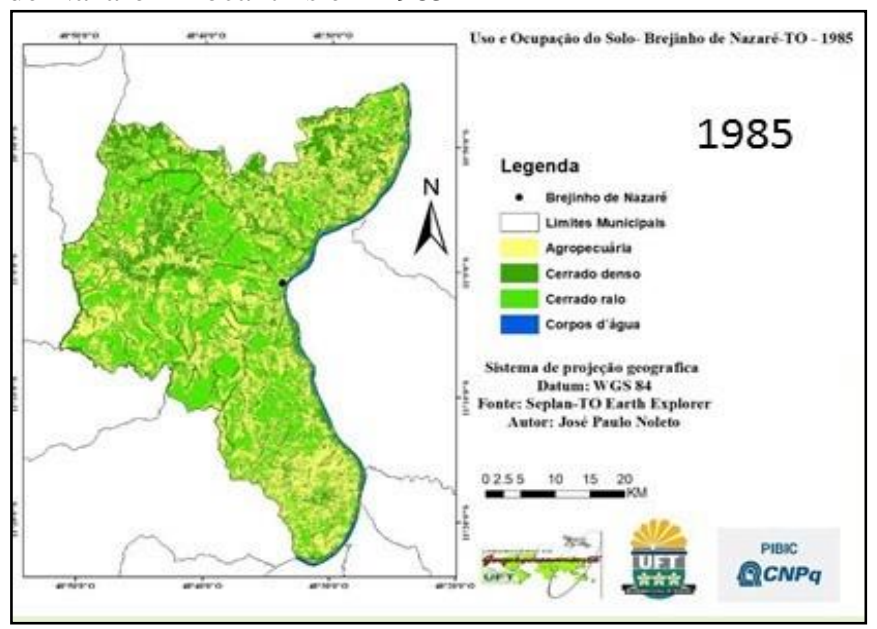

Elaboração: José Paulo da S. Noleto, 2019.

Em 1995 (Figura 3) notasse a presença de cerrado ralo bem distribuído no território municipal e cerrado denso na porção central e noroeste na encosta das serras e acompanhando o fluxo fluvial de rios e córregos.

Figura 3. Uso e Ocupação da Terra do município de Brejinho de Nazaré - Tocantins em 1995

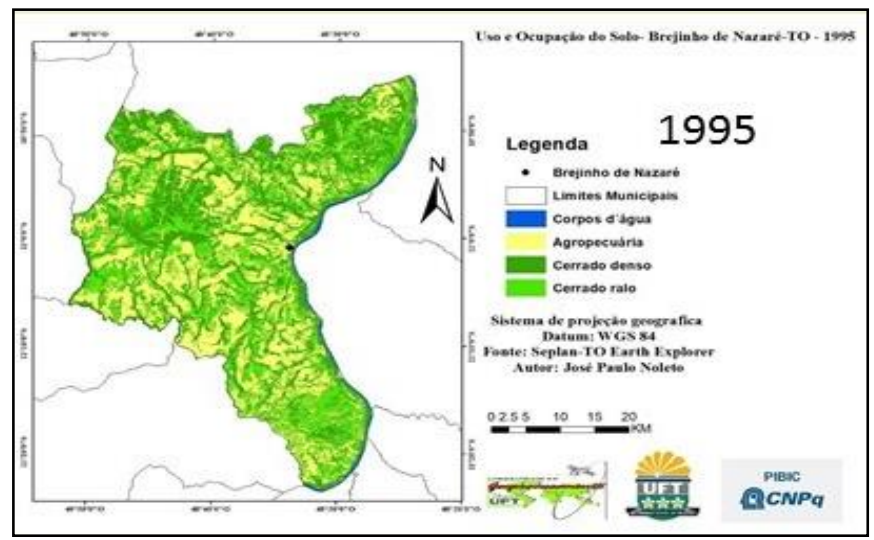

Elaboração: José Paulo da S. Noleto, 2019.

Já os corpos d’água permanecem em uma faixa que se estende no sentido norte-sul, servindo como limite leste do município e em represas e córregos.

A agropecuária está bem distribuída com predomínio na porção sudeste, noroeste, oeste e central do município, a partir desde ano de analise observa-se que já ocupava a maior parte do território municipal.

Em 2005 (Figura 4) o cerrado Ralo e cerrado Denso são mais escassos, com presença nas porções noroeste e central do município, além de estarem distribuídos e conservados em algumas outras localidades como, por exemplo, as proximidades de córregos com as matas ciliar e galeria e, nas encostas de serras.

Figura 4. Uso e Ocupação da Terra do município de Brejinho de Nazaré - Tocantins em 2005

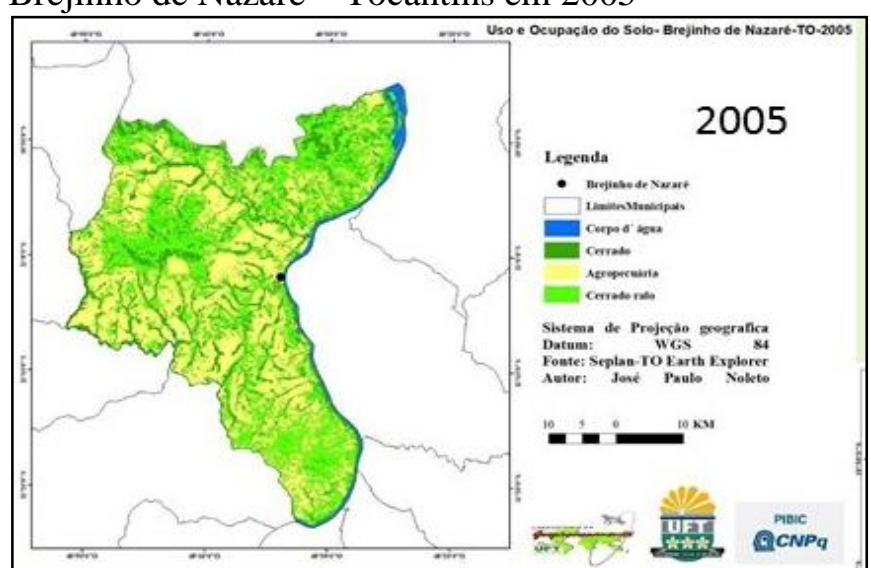

Elaboração: José Paulo da S. Noleto, 2019.

Os corpos de água permanecem concentrados no reservatório da UHE de Lajeado, rio Tocantins, 
delimitando o município e nas porções norte e sul, com represas e córregos distribuídos ao longo do território.

A agropecuária encontrasse com o predomínio de uso nas porções central e sudeste do município com o crescimento de monoculturas e consequentemente a perda de cobertura vegetal natural que antes era de Cerrado e passa a dar lugar aos cultivos agrícolas.

Em 2015 (Figura 5) o Cerrado Ralo e Denso ficaram restritos principalmente as áreas próximas aos cursos fluviais, rios e córregos, e as bordas de serras e relevos mais elevados que se encontram na área de pesquisa.

Neste ano de análise, pode-se observar a redução drástica na área ocupada pela cobertura vegetal nativa de Cerrado, dando lugar as culturas temporárias representadas pelas grandes porções territoriais ocupadas com plantações de soja e milho principalmente. Informações notórias analisadas em trabalho de campo realizado no município.

Os corpos d'água são conservados em algumas pequenas represas e córregos locais, além do reservatório da UHE de Lajeado, no Rio Tocantins.

Figura 5. Uso e Ocupação da Terra do município de Brejinho de Nazaré - Tocantins em 2015

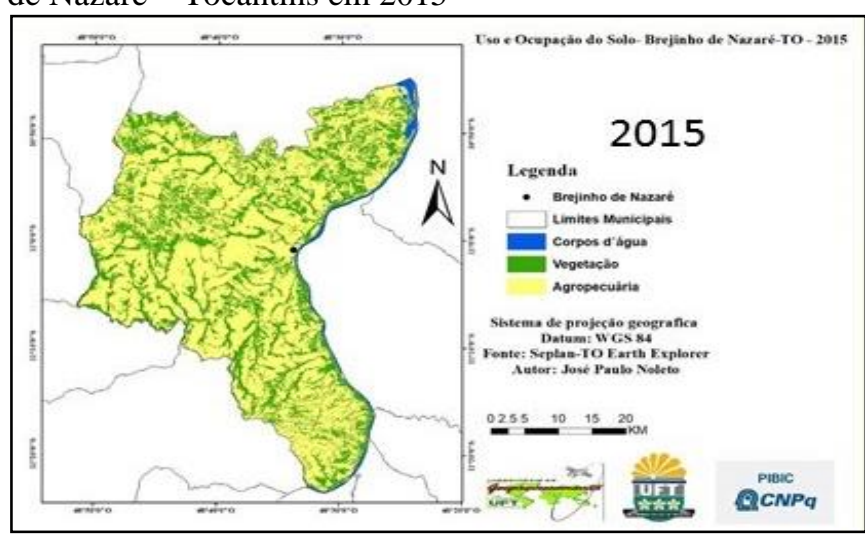

Elaboração: José Paulo da S. Noleto, 2019.

Em 2018 (Figura 6) é possível observar-se alguns aspectos predominantes do uso atual da terra do município de Brejinho de Nazaré onde pode ser destacado o uso na pecuária (criação de gado bovino) e agricultura (soja e milho).
Figura 6. Uso e Ocupação da Terra do município de Brejinho de Nazaré - Tocantins em 2018

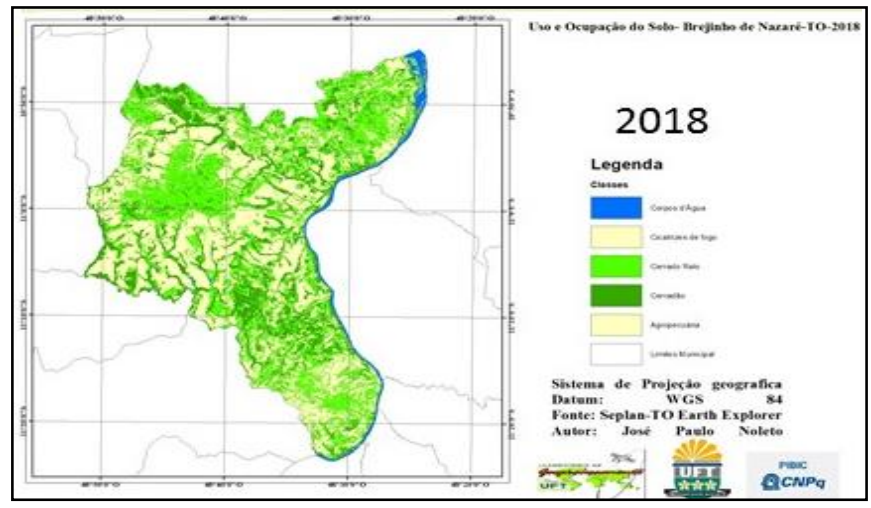

Elaboração: José Paulo da S. Noleto, 2019.

Aspectos do uso atual podem ser visualizados observando-se a Figura 7A onde destaca-se o Cerrado Ralo em primeiro plano e de Cerrado Denso em segundo plano.

A Figura 7B mostra local degradado em uma área de mineração desativada, a Figura 7C mostra o uso com atividades de agropecuária e a Figura 7D permite visualizar aspectos da cobertura vegetal de Cerrado Denso próximo a uma rodovia.

Figura 7. Uso e Ocupação e degradação ambiental do município de Brejinho de Nazaré - 2018

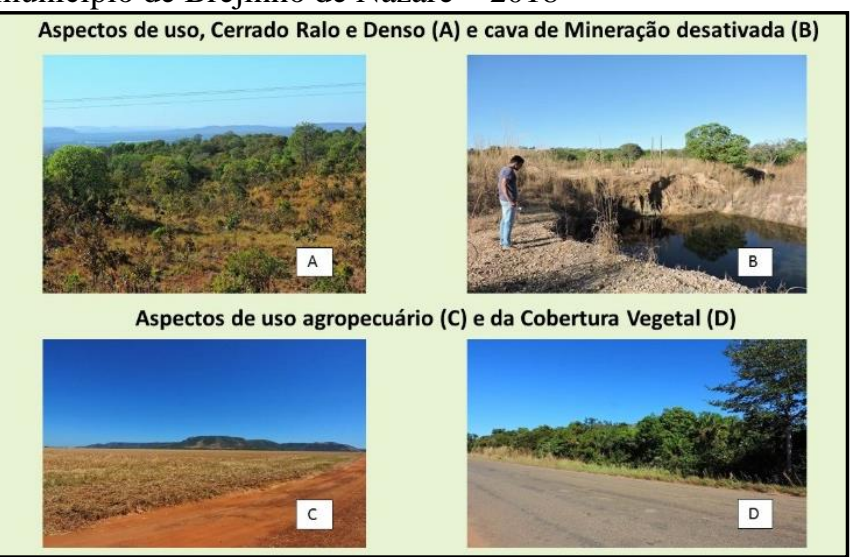

Fonte: Sandro S. V. de Cristo, 2018.

\section{CONCLUSÃO}

De maneira geral, os resultados proporcionaram a observação de significativas transformações ambientais que ocorreram no município de Brejinho de Nazaré, em decorrência do Uso e Ocupação da Terra, destacando-se principalmente a redução da vegetação de 
Cerrado em prol das atividades agropecuárias desenvolvidas.

No mesmo sentido, destaca-se também a importância do uso das técnicas de Sensoriamento Remoto para analisar a evolução e as transformações ambientais e dos aspectos de Uso e Ocupação como ferramenta de gestão ambiental e planejamento de uso, que pode ser utilizado pelos gestores locais.

\section{AGRADECIMENTO}

Ao $\mathrm{CNPq}$ pela concessão de bolsa PIBIC ao aluno (2017 - 2018) e a UFT pelo apoio logístico.

Todos os autores declararam não haver qualquer potencial conflito de interesses referente a este artigo.

\section{REFERÊNCIAS}

BRITO, J. L. S.; PRUDENTE, T. D. Análise temporal de uso do solo cobertura vegetal do município de Uberlândia-MG, utilizando imagens ETM+ LANDSAT 7. Revista Sociedade e Natureza, v.17, 2005. P 37-46.
FERNANDES, M. D. OLIVEIRA, G. H. G. NOBRE, B. A. Sensoriamento Remoto e SIG aplicado no uso e ocupação do solo na bacia do rio são Lamberto no norte de Minas Gerais. <http://unimontes.br/arquivos/2012/geografia_ixerg/ei xo_politica_meio_ambiente/sensoriamentoremoto_e_si g_aplicado_no_uso_e_ocupacao_do_solo_na_bacia_do _rio_sao_lamberto_no_nor.pdf>

MOREIRA, M. A. Fundamentos do Sensoriamento Remoto e metodologias de aplicação. Viçosa - MG: 2. Ed, UFV, 2003.

NOVO, E. M. L. M. Sensoriamento Remoto: princípios e aplicações. São Paulo - SP: Blucher, 2008.

RUFO, L. T.; CRISTO, S. S. V. DE. Sensoriamento remoto aplicado na análise do uso e ocupação da bacia hidrográfica do Córrego Titira. Porto Nacional - TO: Interface, 2014.

SANTOS, A. B; PETRONZIO, J. A. C. Mapeamento de uso e ocupação do solo do município de Uberlândia-MG utilizando técnicas de Geoprocessamento. Anais XV Simpósio Brasileiro de Sensoriamento Remoto - SBSR, Curitiba - PR: INPE, 2011. p.6185.

SILVA NETO, A. A. CRISTO, S. S. V de. Analise do uso e ocupação da bacia hidrográfica do córrego São João através de técnicas do Sensoriamento Remoto, Porto Nacional - Tocantins. Porto Nacional - TO: Monografia de Especialização, 2006. 